\title{
PELAKSANAAN MANAJEMEN PENGAWASAN PENDIDIKAN AGAMA ISLAM DI SMA NEGERI DI KABUPATEN TANAH DATAR
}

\author{
Gusmadi \\ Guru Pendidikan Agama Islam (PAI) di SMA Negeri 1 Lintau Buo Kabupaten Tanah Datar, \\ e-mail: madiputramawar@gmail.com
}

\begin{abstract}
Implementation Monitoring Management PAI in SMA in Tanah Datar. The formulation of the problem (1) How management planning supervisor oversight conducted in SMA PAI Tanah Datar, and (2) How Implementation of management oversight conducted by supervisors PAI in Tanah SMA flat, and (3) How evaluation conducted surveillance management supervisor at SMA PAI Tanah Datar.

The results showed that: the implementation of the management control of Islamic religious education in the District of flat land consists of monitoring the academic supervision and managerial supervision. The findings from the implementation of this monitoring show that: (1) the planning aspect shows that they have prepared a supervision plan, but planning is not fully implemented both academic and managerial supervision, (2) execution of supervisory tasks showed that the supervisor not to mention monitoring well in accordance with the duties and functions of both the supervisory and managerial academic supervisor, and (3) the regulatory aspects of the evaluation indicate that the evaluation does not fully perform his supervision.
\end{abstract}

Kata Kunci: Implementation of Management Control

\section{PENDAHULUAN}

Pengawas sekolah sebagaimana tertuang dalam Keputusan Menteri Negara Pendayagunaan Aparatur Negara Nomor 118 Tahun 1996 Bab I ayat 1 tentang Jabatan Fungsional Pengawas Sekolah dan Angka Kreditnya adalah Pegawai Negeri Sipil yang diberi tugas, tanggungjawab, dan wewenang secara penuh oleh pejabat yang berwenang untuk melakukan pengawasan dengan melaksanakan pembinaan dari segi teknis pendidikan dan administrasi pada satuan pendidikan pra sekolah, pendidikan dasar dan menengah. Dalam rancangan tugasnya Pengawas Sekolah memiliki tanggungjawab besar untuk memantau jalannya sistem pendidikan yang terdapat di sekolah. Pengawas Sekolah memiliki kontribusi besar terhadap pencapaian mutu pendidikan sekolah di atas semua guru yang berperan aktif di dalamnya. 
Pengawas sekolah di lingkungan Direktorat Jenderal Pembinaan Kelembagaan Agama Islam Departemen Agama adalah pengawas Pendidikan Agama Islam (PAI) Dirjen Pendais. Secara struktural mereka tergolong sebagai pegawai negeri sipil yang ditugaskan di lingkungan Kementrian Agama bertugas, bertanggung jawab dan berwewenang penuh terhadap pelaksanaan pembelajaran PAI di sekolah umum serta penyelenggaraan pendidikan di Sekolah dengan melakukan pembinaan dan penilaian dari segi teknis pendidikan dan admininstrasi pada satuan pendidikan prasekolah, pendidikan dasar dan menengah.

Konsep pengawasan demikian sebenarnya menunjukkan pengawasan merupakan bagian dari fungsi manajemen, di mana pengawasan dianggap sebagai bentuk pemeriksaan atau pengontrolan dari pihak yang lebih atas kepada pihak di bawahnya." Dalam ilmu manajemen, pengawasan ditempatkan sebagai tahapan terakhir dari fungsi manajemen. Dari segi manajerial, pengawasan mengandung makna pula sebagai pengamatan atas pelaksanaan seluruh kegiatan unit organisasi yang diperiksa untuk menjamin agar seluruh pekerjaan yang sedang dilaksanakan sesuai dengan rencana dan peraturan.

Persepsi masyarakat terhadap pengawas termasuk pengawas PAI, bahwa pengawas merupakan jabatan untuk sekedar memperpanjang masa kerja sebagai Pegawai Negeri Sipil (PNS) dan menunda masa pensiun, sehingga banyak pejabat struktural yang seharusnya pensiun beralih profesi sebagai pengawas, selain sebagai perpanjangan tangan pemerintah di sekolah, juga sebagai kontrol proses di sekolah, untuk mengetahui titik lemah pelaksanaan program pendidikan. Hal ini menunjukkan pola recruitment dan kinerja pengawas yang mengidap masalah. Atas permasalahan inilah penting untuk mengemukakan secara mendetail kinerja dan tingkat kualifikasi yang harus dimiliki oleh seorang pengawas.

Untuk menetralisasi kesan yang muncul di atas, citra pengawas harus diperbaiki dengan beragam pola yang akhirnya mampu mengantarkan kualitas pengawas baik secara kelembagaan maupun secara personal pada kualitas yang seharusnya. Salah satunya adalah melalui peningkatan kemampuan manajemen kepengawasan, sehingga kedatangan pengawas pada suatu lembaga pendidikan, tidak identik dengan upaya mencari kesalahan guru.

Dalam Al-Qur'an juga tersirat tugas seorang pengawas yang harus berbuat dan bertindak memperbaiki dan mengevaluasi guru-guru dan siswa agar bisa menjalankan tugasnya dengan baik, yaitu terdapat dalam dalam Al-

Qur'an Surat QS.Qaaf ayat 18, sebagai beriku:

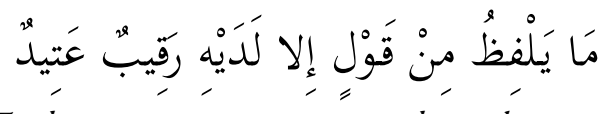

"Tiada suatu ucapanpun yang diucapkannya melainkan ada di dekatnya malaikat pengawas yang selalu hadir."

Peran yang harus dimainkan oleh seorang pengawas sekolah adalah sebagai mitra bagi guru dan kepala sekolah. Sekaligus sebagai pelopor, inovator, kolaborator, penilai, pembimbing, peneliti dan konsultan 
pendidikan. Semuanya tercermin dalam tugas pokok dan fungsi (Tupoksi) pengawas yang intinya adalah melaksanakan pengawasan penyelenggaraan disekolah sesuai dengan penugasan dan peningkatan kualitas proses belajar mengajar dan hasil belajar siswa. Karena begitu pentingnya peran pengawas dalam upaya peningkatan mutu pendidikan, maka pengawas sekolah atau pengawas Pendidikan Agama Islam dituntut untuk melaksanakan tugasnya secara profesional dan penuh tanggung jawab.

Kabupaten Tanah Datar merupakan salah satu kabupaten kota yang ada di Propinsi Sumatera Barat yang mana Kabupaten Tanah Datar terbagi kepada 14 kecamatan yang menyebar dengan jarak cukup berjauhan. di kabupaten Tanah Datar terdapat banyak Sekolah Menengah Atas yang letaknya menyebar di setiap kecamatan

Dari data pengawas yang ada tersebut, yang ditugaskan sebagai pengawas PAI untuk tingkat SD, SLTP dan SLTA di Kabupaten Tanah Datar hannya berjumlah 3 orang yaitu (1). Munir, S.Ag., M.A (2). Aguskar Melfi, M.A (3). Despri Neli, S.Ag melihat kondisi yang demikian maka penulis simpulkan bahwa pengawasan PAI di Kabupaten Tanah Datar sangat kurang, dengan kurangnya pengawas yang ada maka ini menjadi sebuah permasalahan dalam pengawasan guru-guru PAI di Kabupaten Tanah Datar. Sesuai dengan wawancara penulis dengan Kasi PAIS kemenag Kabupaten Tanah Datar, dijelaskan bahwa selama ini sangat kurang pembinaan terhadap Guru-guru PAI dikarenakan kekurangan pengawas dan kurangnya pemahaman pengawas yang ada tentang bagaimana cara dan pola pengawasan yang sesuai dengan teori, hal ini terlihat pada guru-guru yang tidak ada perubahan dalam menjalankan tugasnya sebagai pendidik

Penelitian ini termasuk jenis penelitian kualitatif deskriptif. Menurut Arikunto bahwa penelitian kualitatif deskriptif bersifat eksploratif atau developmental dalam menginterpretasi dan mengambil kesimpulan. Penelitian deskriptif bermaksud mendeskripsikan atau menggambarkan detail dari masalah-masalah penelitian, sehingga dapat diketahui akar pokok permasalahan yang dikaji, sekaligus dapat menyajikan solusi sesuai dengan sifat masalah yang dihadapi. Tujuan utama penelitian deskriptif adalah untuk memberikan gambaran yang jelas dan akurat tentang material atau fenomena yang sedang diselidiki. Deskripsi tersebut dilakukan dengan cara memilah kejadian sehingga dapat digunakan untuk penelitian lebih lanjut.

Menurut Sutrisno Hadi, suatu penelitian (research) sebagian tergantung kepada teknikteknik dalam pengumpulan data. Dari pendapat ini terlihat jelas bahwa teknik pengumpulan data ikut menentukan baik buruknya hasil sebuah penelitian. Dalam penelitian ini, teknik pengumpulan data yang penulis gunakan adalah sebagai berikut :

Wawancara (interview) ialah teknik pengumpulan data dengan dialog yang dilakukan oleh pewawancara untuk memperoleh informasi dari terwawancara, Observasi sebagai metode pengumpulan data dengan cara melakukan pengamatan terhadap obyek penelitian dan Metode pengumpulan 
data secara dokumenter yaitu mencari data dari benda-benda tertulis, seperti buku-buku, majalah, surat kabar, dokumen, peraturanperaturan, notulen rapat, catatan harian, dan sebagainya.

Setelah data yang dibutuhkan terkumpul, maka perlu dilakukan analisis terhadap data tersebut. Bogdan menyebutkan "Analysis involves working with data, organizing it, breaking it intomanageable units, synthesizing searching for pattens, discovering what is important and what be learned and deciding what you will tell others."

Analisis data dalam penelitian kualitatif merupakan proses penyederhanaan data ke dalam bentuk yang mudah dibaca dan diinterprestasikan. Penelitian kualitatif memandang data sebagai produk dari proses memberikan interprestasi peneliti yang di dalamnya sudah terkandung makna yang mempunyai referensi pada nilai. Data yang telah terkumpul dianalisis dengan pendekatan Miles dan Huberman kegiatan analisis terdiri dari tiga alur kegiatan atau proses yang terjadi secara bersamaan yakni: Data Reduction, data display, dan Conclusion Drawing/Verification.

\section{PEMBAHASAN}

Visi dan Misi Pengawas PAI Kementrian Agama Kabupaten Tanah Datar adalah sebagai berikut:

\section{Visi :}

"Terwujudnya sistem pengawasan sekolah dan sekolah untuk membantu terciptanya pendidikan yang berkualitas dan terjangkau serta berwawasan nasional dan global".

\section{Misi :}

a. Membantu mewujudkan kualitas pendidikan sesuai Standar Nasional Pendidikan.

b. Membantu mewujudkan sekolah dan sekolah yang Efektif di Tanah Datar.

c. Membantu revitalisasi dan Kebermaknaan pendidikan.

d. Membantu meningkatkan kepedulian pendidkan terhadap masyarakat yang kurang mampu.

e. Membantu peningkatan peran serta masyarakat terhadap pendidikan.

f. Membantu mengoptimalkan mutu layanan pendidikan.

g. Membantu peningkatan lembaga pendidikan memiliki keunggulan Nasional dan Global.

\section{Daftar Nama dan Job Deskripsi Wilayah Pengawasan}

Pengawas PAI tingkat SLTA di Kantor Kementrian Agama Kabupaten Tanah Datar terdiri dari tiga orang, 1 orang ketua dan 2 orang anggota. Dijelaskan oleh Desfrineli anggota pengawas, pengawas PAI "untuk tinggkat SLTA di kabupaten tanah datar hannya berjumlah 3 orang 1. Munir, M.A yang juga merangkap sebagai kepala pokjawas, 2. Drs. Aguskar Melf 3 Drs. Hj. Desfrineli, M.A. dari tiga orang pengawas ini masing-masing pengawas mempunyai job deskripsi yang berbeda"

Tabel 1.6

Daftar Nama dan Job Deskripsi Wilayah Pengawasan

\begin{tabular}{|c|l|l|l|l|}
\hline NO & \multicolumn{1}{|c|}{ NAMA } & \multicolumn{1}{|c|}{ JABATAN } & $\begin{array}{c}\text { WLAYAH } \\
\text { PENGAWASAN }\end{array}$ & $\begin{array}{c}\text { Jumlah } \\
\text { Sekolah }\end{array}$ \\
\hline \multirow{3}{*}{1} & \multirow{3}{*}{ Munir, M.A } & \multirow{3}{*}{ Ketua } & X koto & 1 \\
& & & Batipuah & 1 \\
& & & Lintau Buo 1 & 1 \\
Lintau Buo 2 & 1 \\
\hline
\end{tabular}




\begin{tabular}{|c|c|c|c|c|}
\hline 2 & $\begin{array}{l}\text { Drs. H. Aguskar } \\
\text { Melfi }\end{array}$ & Anggota & $\begin{array}{l}\text { Pariangan } \\
\text { Rambatan } \\
\text { Rambatan } 2 \\
\text { Padang Gantiang } \\
\text { Sungai Tarab 1 } \\
\text { Sungai Tarab 2 } \\
\end{array}$ & $\begin{array}{l}1 \\
1 \\
1 \\
1 \\
1 \\
1\end{array}$ \\
\hline 3 & $\begin{array}{l}\text { Dra. Hj. Desfrineli, } \\
\text { M.A }\end{array}$ & Anggota & $\begin{array}{l}\text { Batusangkar } 1 \\
\text { Batusangkar } 2 \\
\text { Batusangkar } 3 \\
\text { Sungayang } \\
\text { Salimpauang }\end{array}$ & $\begin{array}{l}1 \\
1 \\
1 \\
1 \\
1\end{array}$ \\
\hline
\end{tabular}

Sumber: Dokumen Pokjawas.

\section{Pelaksanaan Manajemen Pengawasan Akademik}

Pengawasan akademik adalah pengawasan dengan misi utama mengoptimalkan upaya pencapaian sasaran akademik berupa penguasaan murid atas mata pelajaran yang diajarkan dengan tidak mengabaikan tujuan pendidikan yang lainnya, yang bersifat non akademik

Menurut Munir dan Aguskar Melfi, anggota Pengawas PAI Kabupaten Tanah Datar, data hasil pengawasan akademik dapat dimanfaatkan sebagai sumber informasi untuk penilaian terhadap kinerja guru PAI. Sejauh mana guru PAI berhasil meningkatkan pencapaian belajar tentu dapat dilihat pada hasil analisis data kunjungan yang secara periodik dilakukan. Dalam hal ini, setiap guru PAI yang dikunjungi membuat kesepakatan bersama pengawas tentang target pencapaian yang sudah dicapai dan target yang diyakini akan dapat dicapai.

Pelaksanaan pengawasan akademik ini ditekankan kepada guru PAI bahwa misi pengawasan akademik adalah untuk membantu guru PAI dalam meningkatkan keberhasilan mereka untuk menjaga dan meningkatkan mutu nilai-nilai dan pemahaman keagamaan. Jadi lebih merupakan bantuan dan bimbingan teknik dan bukan pengaturan perilaku pada guru PAI.

Peran pengawas PAI dalam pengawasan akademik sebagaimana dijelaskan oleh Roki Ardinal ada empat, yaitu: (1) sebagai nara sumber bagi guru PAI dalam merencanakan dan melaksanakan tugas-tugasnya, serta dalam mendiagnosa keberhasilan, sehingga guru PAI dapat secara terus-menerus meningkatkan kinerjanya; (2) sebagai fasilitator bagi guru PAI dalam mengatasi masalah yang dihadapi maupun dalam mengatasi kekurangan yang dialami dan mengamati pelaksanaan pembelajaran PAI; (3) sebagai motivator yang dengan berbagai cara selalu mengupayakan agar guru PAI mau bekerja lebih bersungguhsungguh dan bersemangat, serta bersamasama kepala sekolah menilai kinerja guru PAI; (4) sebagai aparat pengendali mutu pembelajaran PAI dan menganalisis hasil penilaian (Roki Ardinal, 14-18-2014). Oleh karena itu peran pengawas PAI menjadi sangat penting dalam upaya perbaikan akademik pendidikan agama Islam di sekolah tempat bertugas. Menurut Kepala Kementrian Agama Kabupaten Tanah Datar dalam pelaksanaannya manajemen pengawasan akademik secara umum terdiri dari tiga tahap, tahap perencanaan, pelaksanaan dan evaluasi.:

\section{a. Perencanaan Kerja Pengawasan Akademik}

Tugas-tugas kepengawasan dimulai dengan kegiatan perencanaan. Perencanaan tugas kepengawasan mencakup; (1) program pengawasan tahunan, (2) program pengawasan semesteran, dan (3) program pengawasan akademik dan manajerial. Program pengawasan 
tahunan disusun oleh kelompok kerja pengawas (Pokjawas) di Kabupaten melalui diskusi terprogram. Sedangkan program pengawasan semesteran dilakukan oleh setiap pengawas. Baik perencanaan tahunan maupun semesteran dialokasikan waktu selama 1 minggu. Untuk mengetahui tanggapan responden pengawas tentang kegiatan pelaksanaan perencanaan pengawasan oleh pengawas di Kabupaten Tanah Datar disajikan dalam tabel berikut.

Perencanaan pengawasan dilakukan secara terprogram. Oleh karena itu, sebelum melaksanakan perencanaan, pengawas harus melakukan analisis kebutuhan pengawasan. Hasil wawancara dengan Munir menyatakan bahwa:

"kami mengumpulkan informasi tentang manajemen dan proses pembelajaran pada sekolah-sekolah. Biasanya kami merujuk pada laporan evaluasi tahun sebelumnya. Masalah yang menjadi fokus perencanaan adalah manajemen dan proses pembelajaran di sekolah Pendapat senada diungkapkan oleh Aguskar Melfi bahwa "kami selalu berdiskusi bersama sesama pengawas tentang persoalan di sekolah, hasil itu menjadi referensi ketika merencanakan program pengawasan pada periode berikutnya", Hasil wawancara penulis dengan pengawas yang lain (desfri nelli) juga menjelaskan hal yang senada, "kami pengawas selalu melihat dan mendiskusikan dengan guru-guru masalah kebutuhan dan hal yang menjadi kendala bagi guru dalam menjalankan tugasnya, dan ini menjadi pedoman untuk menyusun perencanaan pengawasan (Desfri Nelli 08-08-2014)
Berdasarkan ketiga pendapat di atas, maka dapat disimpulkan bahwa pengawas pendidikan agama Islam telah melakukan analisis kebutuhan sebagai bahan referensi perencanaan pengawasan. Bentuk perencanaan pengawasan tersebut diimplementasikan ke dalam rencana pengawasan tahunan.

Berdasarkan paparan di atas maka dapat disimpulkan bahwa kegaitan perencanaan pengawasan yang dilakukan oleh pengawas di Kantor Kementerian Agama Kabupaten Tanah Datar telah memenuhi prinsipprinsip perencanaan yang didahului dengan analisis kebutuhan, diharapkan langkah ini, rencana program kepengawasan memenuhi kebutuhan pengembangan dan peningkatan kualitas pengelolaan

\section{b. Pelaksanaan pengawasan akademik}

Kaitan dengan pelaksanaan pengawasan akademik, pengawas PAI Kabupaten Tanah Datar melakukan pengamatan terhadap proses pembelajaran PAI, seperti kegiatan mengajar di kelas, di laboratorium atau di mushalla. Pengawas PAI mencatat kelebihan dan kekurangan guru dalam melaksanakan pembelajaran untuk didiskusikan setelah proses pembelajaran berlangsung. Selama di sekolah, pengawas PAI memberikan penjelasan dan melakukan berbagai upaya agar tidak timbul kesan hubungan antara atasan dan bawahan atau hubungan antara pemeriksa dan yang diperiksa, sebaliknya yang dicipta adalah suasana kemitraan sehingga tidak dirasakan sebagai beban bagi guru PAI dan kepala sekolah. 
Para pengawas hanya melakukan pengawasan dan pembinaan terhadap kegiatan akademik dan manajerial. Kegiatan pembinaan, pemantauan dan penilaian Standar Nasional Pendidikan tidak dilakukan, karena secara nasional Standar Nasional Pendidikan belum terpenuhi. Hal ini diungkapkan oleh Munir "kami hanya fokus melakukan pada pengawasan terhadap pelaksanaan program pembelajaran dan manajemen kepala sekolah, karena asumsinya, meski dengan sumberdaya yang ada, jika guru dan kepala sekolah dapat mengelolanya dengan baik, maka dapat meningkatkan mutu pendidikan di sekolah" (Munir, 14-08-2014).

Berdasarkan pendapat di atas maka dapat disimpulkan bahwa pengawasan yang dilakukan hanya pada aspek akademik dengan menjadikan guru sebagai sasaran pengawasan serta pengawasan manajerial dengan menjadikan kepala sekolah sebagai sasaran pengawasan.

Berdasarkan hasil wawancara penulis dengan Munir menunjukkan bahwa secara umum pelaksanaan tugas pengawasan dalam memberikan pembinaan penyusunan perangkat pembelajaran masih sangat rendah. Hal ini terlihat bahwa tidak banyak guru-guru PAI yang betul-betul paham dengan bagaimana cara penyusunan program tahunan ini, hall ini juga dijelaskan oleh Roki Ardinal di ruangan kasi PAIS “sangat tidak efektif bagi pengawas melakukan pembinaan dengan waktu yang sangat sedikit sekali, sehingga ini lah yang menyebabkan guru kurang memahami bagaimana cara pembuat dan menyusun program tahunan ini dan program semesteran, (Roki Ardinal, 14-18-2014), maka dapat disimpulkan bahwa pembinaan penyusunan perangkat pembelajaran masih sangat rendah.

\section{c. Evaluasi}

Permasalahan berikutnya yang penulis teliti dalam penelitian ini adalah tentang evaluasi supervisi akademik oleh pengawas terhadap guru. Dalam hal ini juga ada beberapa pertanyaan yang penulis ajukan kepada pengawas yaitu sebagaimana diuraikan berikut ini.

Pertanyaan pertama menyangkut tentang apa saja yang dilakukan oleh pengawas dalam melakukan evaluasi akademik. Untuk memperoleh informasi mengenai hal ini penulis mengadakan wawancara langsung dengan pengawas. Dari wawancara tersebut diketahui halhal berikut ini: "Setelah melakukan pembinaan pengawasan kami juga mengevaluasi Temuan yang sering dijumpai dalam supervisi akademik adalah masalah perangkat pembelajaran yang belum lengkap." (Munir, 14-18-2014). Pengawas yang lain juga menyebutkan sebagai berikut: "Yang sering menjadi temuan bagi kami dilapangan adalah perangkat pembelajaran guru yang belum lengkap, sehingga guru tidak siap ketika pengawas melakukan supervisi (Desfri Nelli, 14-18-2014).. Disamping itu, kalau pengawas melakukan kunjungan 
kelas juga ada temuan seperti penggunaan media dan metode yang kurang efektif dalam pembelajaran."

Hal selanjutnya yang penulis teliti adalah tindak lanjut yang dilakukan pengawas terhadap temuan-temuan hasil supervisi yang dijumpai tersebut. Dalam hal ini penulis menemukan informasi dari pengawas sebagai berikut: "Setelah dilakukan supervisi, tindak lanjut yang diberikan terhadap guru adalah meminta guru agar melengkapi atau menyempurnakan perangkat pembelajaran yang belum lengkap. (Aguskar Melfi, 14-18-2014). Dan yang berkaitan dengan media ataupun metode pembelajaran, pengawas memberikan saran tentang media dan metode yang lebih efektif dalam pembelajaran tersebut."

Mengenai hal ini juga diperkuat oleh pernyataan pengawas lain yang menyebutkan: "Tindak lanjutnya tentu saja guru harus melengkapi perangkat pembelajarannya. Kalau yang berhubungan dengan media pembelajaran, diberikan saran untuk menggunakan media yang tepat." Pernyataan pengawas tersebut juga dibenarkan oleh katua pokjawas, yang menyebutkan dalam wawancara terdahulu bahwa bagi guru yang tidak lengkap perangkatnya, mendapat teguran dari pengawas dan diminta untuk melengkapi. Kemudian untuk supervisi proses pembelajaran, pengawas juga menjelaskan bahwa setelah disupervisi guru kemudian dipanggil oleh pengawas secara face to face, dan diajak berdiskusi membicarakan berbagai hal yang masih kurang efektif dalam pembelajaran. Setelah itu pengawas memberikan arahan dan saran-saran untuk perbaikan bagi guru di masa yang akan datang.

Dari uraian tentang evaluasi supervisi akademik oleh pengawas di atas, dapat disimpulkan bahwa kegiatan mengevaluasi tersebut telah dilaksanakan oleh pengawas. Adapun temuan yang sering dijumpai pengawas dalam melaksanakan supervisi akademik terhadap guru adalah, pertama, administrasi perencanaan pembelajaran atau yang lebih sering disebut dengan perangkat pembelajaran, yang tidak lengkap. Kedua, penggunaan media yang belum optimal. Dan yang ketiga, pemakaian metode yang kurang efektif.

\section{PENUTUP}

\section{Kesimpulan}

Secara keseluruhan pelaksanaan manajemen pengawasan ini memenukan kecenderungan belum optimalnya kegiatan pelaksanaan pengawasan di Kantor Kementerian Agama Kabupaten Tanah Datar. Terdapat banyak aspek yang belum mencapai standar pengawasan mencakup aspek kapasitas pengawas, pelaksanaan tugas kepengawasan, dan hasil pengawasan. Secara rinci, kesimpulan hasil pelaksanaan pengawasan ini diuraikan sebagai berikut:

\section{a. Aspek perencanaan}

Pada aspek perencanan, sudah disusun secara baik sesuai dengan petunjuk pelaksanaan pengawasan, Perencanaan pengawasan 
yang dilakukan oleh pengawas di Kantor Kementerian Agama Kabupaten Tanah Datar telah memenuhi prinsip-prinsip perencanaan yang didahului dengan analisis kebutuhan, diharapkan rencana program kepengawasan memenuhi kebutuhan pengembangan dan peningkatan kualitas pengelolaan pendidikan pada tingkat satuan pendidikan.

\section{b. Aspek pelaksanaan}

Aspek pelaksanaan tugas kepengawasan mencakup tiga komponen yakni, perencaaan, pelaksanaan, dan penilaian yang meliputi dua kateogori supervisi, yakni supervisi akademik dan supervisi manajerial. Pada aspek perencanaan, pengawas secara kolektif telah menyusun rencana kerja kepengawasan. Pada tahap implementasi, rencana kerja belum terlaksana secara optimal baik dalam supervisi akademik maupun manajerial.

\section{c. Aspek Evaluasi}

Aspek Evaluasi, pengawas belum menunjukkan evaluasi yang optimal terhadap perbaikan pengelolaan pendidikan pada Sekolah.

\section{Saran}

Berdasarkan kesimpulan di atas maka, beberapa saran yang dapat dijadikan sebagai pertimbangan dalam upaya memperbaiki efektivitas tugas dan fungsi kepengawasan adalah sebagai berikut:

a. Pihak pengambil kebijakan dalam hal ini kantor kementerian agama, agar menjadikan jabatan pengawas sebagai jabatan profesional yang membutuhkan seperangkat kompetensi sehingga memiliki kompetensi dalam menjalankan tugas dan fungsinya.

b. Kepada para pengawas pendidikan, agar secara kreatif terus melakukan peningkatan kompetensi diri melalui berbagai sarana dan sumber belajar, sehingga menunjukkan peran dan kontribusinya dalam pengelolaan pendidikan di sekolah.

c. Melakukan perbaikan manajemen kepengawasan sehingga pengawas dalam menjalankan tugas dan fungsinya lebih terkontrol. Di samping itu, pelibatan peran serta pengawas dalam pengambilan kebijakan pendidikan di lingkup kantor kementerian agama sebagai bagian dari bentuk pemberdayaan pejabat pengawas dalam tata kelola pendidikan di sekolah.

\section{KEPUSTAKAAN ACUAN}

Abdul Majid, Perencanaan Pembelajaran Mengembangkan Standar Kompetensi Guru, Bandung: PT. Remaja Rosdakarya, 2007

Aqib, Zainal dan Elham Rohmanto, Membangun Profesionalisme Guru dan Pengawas Sekolah, (Bandung: Yrama Widya. 2007

Aqib, Zainal Profesionalisme Guru dalam Pembelajaran, (Surabaya: Insan Cendekia, 2002

Arsyad, Azhar, Pokok Pokok Manajemen, (Yogyakarta: Pustaka Pelajar. 2002 
Atmodiwirio, Soebagio, Manajemen Pendidikan Indonesia, (Jakarta: Ardadizya Jaya. 2000).

Buchori, Mochtar, Spektrum Problematika Pendidikan di Indonesia, (Yogyakarta: Tiara Wacana, 1994

George R Terry, dan Leslie W. Rue, Principles of Management (Terj.), (Jakarta: Bumi aksara. 2000

Hasan, Yusuf A., et. al., Pedoman Pengawas untuk Madrasah dan Pengawas Madrasah dan Sekolah Umum, (Jakarta: Mekar Jaya, 2002

Imam Tolkhah, Manajemen Madrasah Aliyah, Jakarta: (Direktorat Jendral Kelembagaan Agama Islam Depag RI. 1988

Matthew B. Miles dan A. Micheal Huberman, Kualitative data Analysis An Expanded Source Book (California: Saga Publication, Inc, 1994), p. 11

Mulyono, Manajemen Administrasi \& Organisasi Pendidikan, (Yogyakarta: ArRuzz Media. 2008
Sahertian, Piet A., Supervisi Pendidikan, (Jakarta: Renika Cipta, 2000

Sugiyono, Metode Penelitian Pendidikan (Pendekatan Kuantitatif, Kualitatif, dan $R \& D$ ), (Bandung: Alfabeta. 2006

Suharsimi Arikunto, Prosedur Penelitian: Suatu Pendekatan Praktik, Jakarta : Rineka Cipta. 2006

Suyanto, Dinamika Pendidikan Nasional: dalam Percaturan Dunia Global, Jakarta: PSAP Muhammadiyah, 2006

Syaiful Segala, Manajemen Strategik dalam Peningkatan Mutu Pendidikan, Bandung: Alfabeta, 2007

Thaib, M. Amin BR., dkk., Profesionalisme Pelaksanaan Pengawasan Pendidikan, (Jakarta: Depag RI Direktorat Jendral Kelembagaan Agama Islam, Direktorat Madrasah dan Pendidikan Agama Islam pada Sekolah Umum 2005),

Zainal Aqib, Profesionalisme Guru dalam Pembelajaran, Surabaya: Insan Cendekia, 2002 